\title{
Hybrid coronary revascularization versus coronary artery bypass surgery with bilateral or single internal mammary artery grafts
}

\author{
Joshua M. Rosenblum, MD, PhD, ${ }^{a}$ Ralf E. Harskamp, MD, ${ }^{\mathrm{b}}$ Niels Hoedemaker, MD, ${ }^{\mathrm{c}}$ Patrick Walker, MD, ${ }^{\mathrm{a}}$ \\ Henry A. Liberman, MD, ${ }^{a}$ Robert J. de Winter, MD, PhD, ${ }^{c}$ Thomas A. Vassiliades, MD, ${ }^{d}$ \\ John D. Puskas, MD, ${ }^{e}$ and Michael E. Halkos, MD ${ }^{a}$
}

\section{ABSTRACT}

Objective: Hybrid coronary revascularization (HCR) combines minimally invasive left internal mammary artery (LIMA)-left anterior descending artery (LAD) bypass with percutaneous intervention of non-LAD vessels. The purpose of this study was to compare outcomes of HCR to conventional coronary artery bypass graft $(\mathrm{CABG})$ surgery with single internal mammary artery (SIMA) or bilateral internal mammary artery (BIMA) grafting.

Methods: Between October 2003 and September 2013, 306 consecutive patients who underwent HCR were compared with 8254 patients who underwent CABG with SIMA $(7381 ; 89.4 \%)$ or BIMA $(873 ; 10.6 \%)$ at a US academic center. The primary outcome was a composite of 30-day death, myocardial infarction, and stroke (major cerebrovascular and cardiac event [MACCE]). In addition to multiple logistic and linear regression analysis, a propensity score-matched analysis was used to compare HCR with SIMA and with BIMA.

Results: The Society of Thoracic Surgeons-predicted risk of mortality was $1.6 \%$ for HCR, $2.1 \%$ for SIMA, and $1.1 \%$ for BIMA $(P<.001)$. Factors associated with HCR use were older age, lower body mass index, history of percutaneous coronary intervention, and 2-vessel disease. In propensity-matched groups, 30-day MACCE rates were comparable $(3.3 \%$ for HCR vs $1.3 \%$ for BIMA [odds ratio (OR), 2.50; $P=.12$ ] and vs $3.6 \%$ for SIMA [OR, $1.00 ; P=1.00])$. In-hospital complications were lower after HCR versus SIMA or BIMA (OR, 0.59; $P=.033$ and OR, 0.55; $P=.015$, respectively), as was the need for blood transfusion (OR, $0.44 ; P<.001$ and OR, 0.57; $P<.001)$. HCR was associated with shorter hospital stay compared with SIMA (OR, 1.28; $P=.038$ ) or BIMA (OR, 1.40; $P=.006$ ). No survival difference between matched groups was found at midterm follow-up (HCR vs SIMA: hazard ratio [HR], 0.66; 95\% confidence interval [CI], 0.32-1.38; $P=.66$; HCR vs BIMA: HR, $1.05 ; 95 \% \mathrm{CI}, 0.48-2.29 ; P=.91)$.

Conclusions: HCR may represent a safe, less invasive alternative to conventional CABG in carefully selected patients, with similar short-term and midterm outcomes as CABG performed with either SIMA or BIMA grafting. (J Thorac Cardiovasc Surg 2016;151:1081-9)

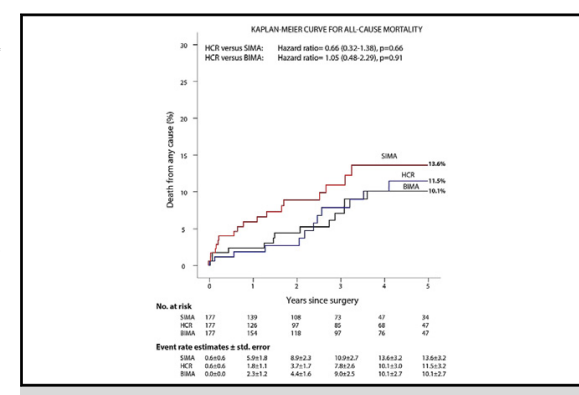

Adjusted survival is equivalent in HCR and traditional CABG.

Central Message

Hybrid coronary revascularization is safe and durable compared with surgical revascularization with single or bilateral mammary grafts.

\section{Perspective}

In patients with multivessel CAD and favorable coronary anatomy, HCR may be an acceptable alternative to traditional CABG surgery. We show that short-term and mid-term outcomes are equivalent between the approaches in the appropriate patient populations.

See Editorial Commentary page 1090.

\footnotetext{
From the a Divisions of Cardiothoracic Surgery and Cardiology, Clinical Research Unit, Emory University School of Medicine, Atlanta Ga; ${ }^{b}$ Department of Cardiology, VU University Medical Center, Amsterdam, The Netherlands; cAcademic Medical Center, University of Amsterdam, The Netherlands; ${ }^{\mathrm{d}}$ Medtronic Inc, Mounds View, Minn; and ${ }^{\mathrm{e}}$ Department of Cardiothoracic Surgery, Mount Sinai Beth Israel, New York, NY.

Received for publication June 11, 2015; revisions received Oct 19, 2015; accepted for publication Oct 21, 2015; available ahead of print Dec 11, 2015.

Address for reprints: Michael E. Halkos, MD, Division of Cardiothoracic Surgery, Emory University School of Medicine, 550 Peachtree St NE, 6th Floor, MOT, Atlanta, GA 30308 (E-mail: mhalkos@emory.edu).

$0022-5223 / \$ 36.00$

Copyright (C) 2016 by The American Association for Thoracic Surgery http://dx.doi.org/10.1016/j.jtcvs.2015.10.061
}

In patients with multivessel coronary artery disease (CAD) and favorable coronary anatomy, hybrid coronary revascularization (HCR), which combines a minimally invasive, sternal-sparing left internal mammary artery

Scanning this QR code will take you to the article title page.

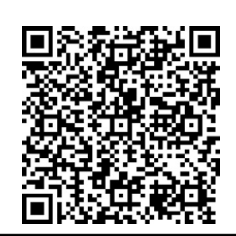




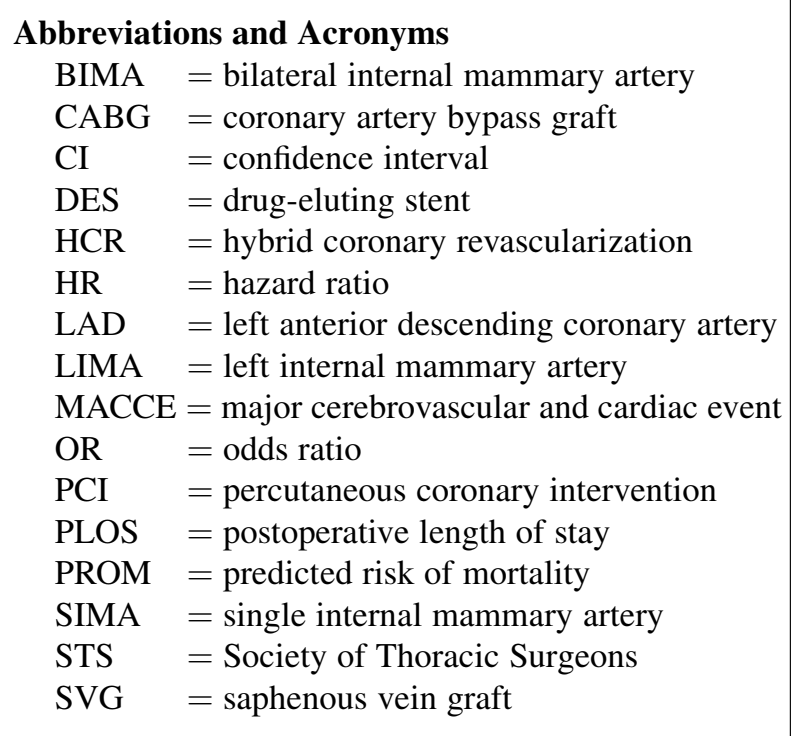

(LIMA)-to-left anterior descending (LAD) bypass with percutaneous coronary intervention (PCI) of non-LAD lesions, may be an acceptable alternative to traditional multivessel coronary artery bypass graft (CABG) surgery. ${ }^{1,2}$ Compared with CABG, HCR offers the advantages of a less invasive technique, which may lead to faster recovery and fewer in-hospital complications. ${ }^{3,4}$ Theoretically, drug-eluting stents (DESs) are substituted for the saphenous vein graft (SVG) for non-LAD lesions and may be of comparable efficacy, given the overall poor long-term patency rates of vein grafts. ${ }^{5,6}$

We have previously shown that HCR has comparable efficacy and improved short-term results compared with traditional CABG (LIMA plus SVG) in carefully selected patients. ${ }^{7-9}$ The long-term durability, improved patency rates, ${ }^{10}$ and potential survival advantage ${ }^{11}$ of using both internal mammary arteries has received considerable attention as the optimal revascularization strategy, yet its adoption has been limited by the increased technical challenges and concerns about increased sternal complications. ${ }^{12-14}$ Criteria for selecting the most suitable candidates for a hybrid approach versus conventional CABG remain unclear. ${ }^{15}$ Therefore, the goals of the present study were to compare the short-term and midterm results of HCR and CABG using either a single internal mammary artery (SIMA) or bilateral internal mammary artery (BIMA) revascularization strategy, and to assess preoperative patient selection criteria predictive of the use of HCR versus CABG in a single academic institution with experience in all 3 strategies.

\section{PATIENTS AND METHODS}

\section{Study Population and Definitions}

Eligible cases performed between October 2003 and September 2013 at Emory University were identified from the institutional Society of Thoracic Surgeons (STS) database. A custom data field was created within the STS
Starting Population

All patients in the STS Database who underwent coronary bypass surgery at Emory University between 2003-13 ( $n=9901)$

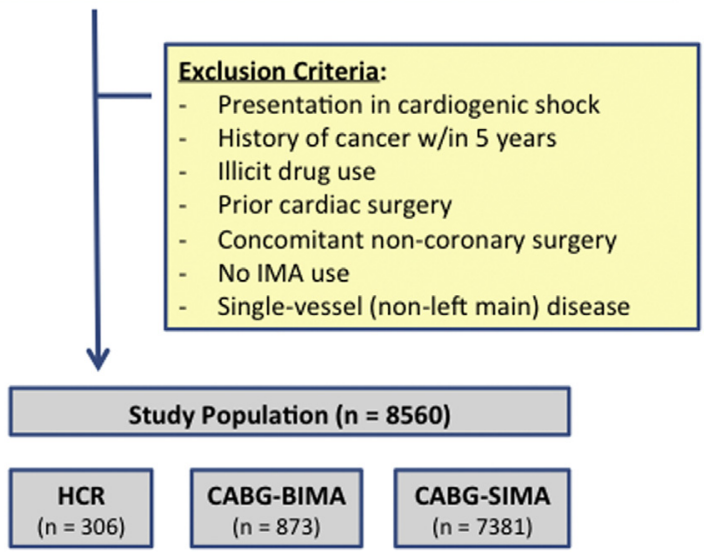

FIGURE 1. Study population derivation and exclusion criteria. $S T S$, Society of Thoracic Surgeons; HCR, hybrid coronary revascularization; $C A B G$, coronary artery bypass graft; $B I M A$, bilateral internal mammary artery; SIMA, single internal mammary artery.

database that defined HCR patients on an intent-to-treat basis, where HCR involved a planned minimally invasive LIMA-to-LAD bypass with PCI of at least 1 non-LAD lesion. Exclusion criteria and study group breakdown are shown in Figure 1. This study was conducted with the approval of Emory University's Institutional Review Board.

\section{Patient Selection and Procedural Information}

We previously published our recommendations for the use of a hybrid revascularization approach ${ }^{16,17}$ and selection of SIMA versus BIMA. ${ }^{18}$ BIMA grafting was generally reserved for younger patients with a second favorable target for an additional arterial graft, but patients with poorly controlled diabetes (defined as glycosylated hemoglobin $>7 \%$ ), morbid obesity (body mass index $[\mathrm{BMI}]>35$ ), immunosuppression, and moderate to severe lung disease were usually not considered candidates. The decision for BIMA grafting was ultimately determined by surgeon discretion and preference. Angiographic indications for HCR were the presence of a significant stenosis $(>70 \%)$ in the proximal LAD, LAD anatomy amenable to minimally invasive LIMA-LAD bypass, and non-LAD lesions amenable to routine PCI. Relative contraindications for HCR included hemodynamic instability, previous cardiac or thoracic surgery, severe lung disease with the inability to tolerate single-lung ventilation, and morbid obesity. In most HCR procedures, LIMA-LAD revascularization was performed first.

We have found that this approach allows the surgical portion of the procedure to be performed without concern for bleeding associated with dual antiplatelet therapy or an inability to reverse anticoagulation. Moreover, this approach allows for interrogation of the LIMA graft before PCI. A PCI-first strategy was routinely used in patients who presented with acute coronary syndromes in which the non-LAD vessel was the culprit lesion. For all of these patients, robotic-assisted LIMA-LAD grafting was performed on dual antiplatelet therapy. Most HCR patients underwent CABG and PCI during the index hospitalization.

Between 2003 and 2009, LIMA harvest for HCR cases was performed endoscopically; thereafter, LIMA harvest was achieved with robotic assistance (DaVinci Robotic Surgical System; Intuitive Surgical, Sunnyvale, Calif). After identification of the optimal target site on the LAD, an off-pump LIMA-LAD anastomosis was performed through a non-rib spreading, 3- to 4-cm mini-thoracotomy, using a minimally invasive stabilizer (Nuvo; Medtronic, Minneapolis, Minn). PCI was performed using standard techniques with either a first-generation (sirolimus or paclitaxel) or second-generation (everolimus or zotarolimus) DES. 
TABLE 1. Baseline patient characteristics

\begin{tabular}{|c|c|c|c|c|c|c|c|}
\hline \multirow[b]{2}{*}{ Variable } & \multicolumn{4}{|c|}{ Complete study population } & \multicolumn{3}{|c|}{ Matched study population } \\
\hline & $\begin{array}{c}\text { HCR } \\
(n=306)\end{array}$ & $\begin{array}{c}\text { BIMA } \\
(\mathbf{n}=\mathbf{8 7 3})\end{array}$ & $\begin{array}{c}\text { SIMA } \\
(n=7381)\end{array}$ & $P$ value & $\begin{array}{c}\text { HCR } \\
(n=306)\end{array}$ & $\begin{array}{c}\text { BIMA } \\
(n=306)\end{array}$ & $\begin{array}{c}\text { SIMA } \\
(\mathbf{n}=306)\end{array}$ \\
\hline Age, y mean \pm SD & $64.4 \pm 11.9$ & $59.0 \pm 10.1$ & $63.8 \pm 10.6$ & $<.001$ & $64.4 \pm 11.9$ & $62.5 \pm 9.8$ & $63.3 \pm 10.7$ \\
\hline Female sex, n $(\%)$ & $91(29.7)$ & $135(15.5)$ & $2117(28.7)$ & $<.001$ & $91(29.7)$ & $78(25.5)$ & $94(30.7)$ \\
\hline Caucasian, n (\%) & $241(78.8)$ & $663(75.9)$ & $5660(76.7)$ & .61 & $241(78.8)$ & $238(77.8)$ & $246(80.4)$ \\
\hline Height, $\mathrm{cm}$, mean $\pm \mathrm{SD}$ & $172.4 \pm 10.0$ & $174.5 \pm 10.1$ & $172.3 \pm 11.0$ & $<.001$ & $172.4 \pm 10.0$ & $173.2 \pm 9.5$ & $172.6 \pm 9.6$ \\
\hline Weight, $\mathrm{kg}$, mean $\pm \mathrm{SD}$ & $84.4 \pm 17.7$ & $89.3 \pm 17.8$ & $87.4 \pm 20.3$ & .001 & $84.4 \pm 17.7$ & $86.7 \pm 17.5$ & $85.1 \pm 19.9$ \\
\hline Body mass index, $\mathrm{kg} / \mathrm{m}^{2}$, mean $\pm \mathrm{SD}$ & $28.3 \pm 5.3$ & $29.8 \pm 13.5$ & $29.7 \pm 12.7$ & .15 & $28.3 \pm 5.3$ & $28.9 \pm 5.3$ & $28.5 \pm 5.9$ \\
\hline Current smoker, n (\%) & $63(20.6)$ & $262(30.0)$ & $2082(28.2)$ & .006 & $63(20.6)$ & $73(23.9)$ & $70(22.9)$ \\
\hline Diabetes mellitus, n (\%) & $113(36.9)$ & $241(27.6)$ & $3232(43.8)$ & $<.001$ & $113(36.9)$ & $104(34.0)$ & $119(38.9)$ \\
\hline Cerebrovascular disease, $\mathrm{n}(\%)$ & $53(17.3)$ & $101(11.6)$ & $1389(18.8)$ & $<.001$ & $53(17.3)$ & $49(16.0)$ & $57(18.6)$ \\
\hline Chronic lung disease, $\mathrm{n}(\%)$ & $11(3.6)$ & $16(1.8)$ & $489(6.3)$ & $<.001$ & $11(3.6)$ & $8(2.6)$ & $12(3.9)$ \\
\hline Dyslipidemia, n (\%) & $280(91.5)$ & $756(86.6)$ & $6248(84.6)$ & .002 & $280(91.5)$ & $282(92.2)$ & $282(92.2)$ \\
\hline Hypertension, n (\%) & $280(91.5)$ & $728(83.4)$ & $6523(88.4)$ & $<.001$ & $280(91.5)$ & $278(90.8)$ & $279(91.2)$ \\
\hline Peripheral artery disease, $\mathrm{n}(\%)$ & $34(11.1)$ & $97(11.1)$ & $1208(16.4)$ & $<.001$ & $34(11.1)$ & $36(11.8)$ & $28(9.2)$ \\
\hline Renal failure, n (\%) & $19(6.2)$ & $25(2.9)$ & $487(6.6)$ & $<.001$ & $19(6.2)$ & $12(3.9)$ & $15(4.9)$ \\
\hline $\mathrm{eGFR}$, mean $\pm \mathrm{SD}$ & $75.0 \pm 27.0$ & $77.9 \pm 23.2$ & $71.0 \pm 25.4$ & & $75.0 \pm 27.0$ & $77.2 \pm 25.8$ & $79.1 \pm 29.2$ \\
\hline Hemoglobin $\mathrm{g} / \mathrm{dL}$, mean $\pm \mathrm{SD}$ & $13.0 \pm 1.8$ & $13.8 \pm 3.1$ & $13.1 \pm 2.0$ & $<.001$ & $13.0 \pm 1.8$ & $13.2 \pm 1.7$ & $13.2 \pm 1.7$ \\
\hline Previous myocardial infarction, $\mathrm{n}(\%)$ & $145(47.4)$ & 405 (46.4) & $3949(53.5)$ & $<.001$ & $145(47.4)$ & $140(45.8)$ & $148(48.4)$ \\
\hline Heart failure $<14 \mathrm{~d}, \mathrm{n}(\%)$ & $38(12.4)$ & $115(13.2)$ & $1768(24.0)$ & $<.001$ & $38(12.4)$ & $34(11.1)$ & $40(13.1)$ \\
\hline $\mathrm{LVEF} \%$, mean $\pm \mathrm{SD}$ & $54.5 \pm 9.4$ & $52.2 \pm 11.0$ & $51.7 \pm 12.4$ & $<.001$ & $54.5 \pm 9.4$ & $54.2 \pm 10.7$ & $54.9 \pm 10.2$ \\
\hline Isolated left main disease, $\mathrm{n}(\%)$ & $34(11.1)$ & $66(7.6)$ & $613(8.3)$ & $<.001$ & $34(11.1)$ & $37(12.1)$ & $31(10.1)$ \\
\hline Left main + other vessel, $\mathrm{n}(\%)$ & $28(9.2)$ & $185(21.2)$ & $1734(23.5)$ & $<.001$ & $28(9.2)$ & $33(10.8)$ & $37(12.1)$ \\
\hline 3-vessel disease, $\mathrm{n}(\%)$ & $104(34.0)$ & $471(54.0)$ & $3696(50.1)$ & $<.001$ & $104(34.0)$ & $124(40.5)$ & $102(33.3)$ \\
\hline Aspirin use, n (\%) & $241(78.8)$ & $736(84.3)$ & $5982(81.0)$ & .043 & $241(78.8)$ & $248(81.0)$ & $233(76.1)$ \\
\hline Beta blocker use, n (\%) & $254(83.0)$ & $693(79.4)$ & $5792(78.5)$ & .32 & $254(83.0)$ & $243(79.3)$ & $254(83.0)$ \\
\hline STS PROM, mean \pm SD & $1.6 \pm 2.2$ & $1.1 \pm 1.8$ & $2.1 \pm 2.8$ & $<.001$ & $1.6 \pm 2.2$ & $1.4 \pm 0.3$ & $1.7 \pm 0.4$ \\
\hline STS risk morbidity/mortality, mean \pm SD & $11.9 \pm 9.1$ & $10.0 \pm 6.7$ & $14.0 \pm 9.8$ & $<.001$ & $11.9 \pm 9.1$ & $11.2 \pm 8.7$ & $11.7 \pm 9.0$ \\
\hline Year of procedure, mean \pm SD & $2009 \pm 3$ & $2008 \pm 3$ & $2007 \pm 3$ & $<.001$ & $2009 \pm 3$ & $2008 \pm 3$ & $2009 \pm 3$ \\
\hline
\end{tabular}

$H C R$, Hybrid coronary revascularization; BIMA, bilateral internal mammary artery; SIMA, single internal mammary artery; SD, standard deviation; $e G F R$, estimated glomerula filtration rate; $L V E F$, left ventricular ejection fraction; STS, Society of Thoracic Surgeons; PROM, predicted risk for mortality.

\section{Outcomes of Interest and Definitions}

Outcomes were defined as in the STS Adult Cardiac Surgery Database (www.sts.org) and included the composite of death, stroke, and myocardial infarction (MI) at 30 days, termed a major cerebrovascular and cardiac event (MACCE). In-hospital outcome metrics were defined as any reoperation, renal failure, prolonged ventilation (for $>24$ hours), deep sternal wound infection, CABG-related bleeding, ${ }^{19}$ need for blood transfusion, and short or long postoperative length of stay (PLOS). All-cause mortality up to maximum of 5 years was obtained by querying the Social Security Death Index to determine dates of death up to January 1, 2011.

CABG-related bleeding is a standardized metric for clinical trials reporting, defined by a consortium of independent academic research organizations, professional societies, federal agencies, and independent consultants with the goal of better understanding how prevention of major bleeding improves outcomes in contemporary treatment of acute coronary syndromes. For the purpose of this study, CABG-related bleeding was defined as perioperative intracranial bleeding within 48 hours, reoperation after closure of chest for the purpose of controlling bleeding, chest tube output $\geq 2 \mathrm{~L}$ within a 24-hour period, and/or transfusion of $\geq 5 \mathrm{U}$ whole blood or packed red blood cells (excluding cell-saver products) within a 48-hour period.

\section{Statistical Analysis}

Continuous variables were compared using the Kruskal-Wallis test, and categorical variables were compared using the $\chi^{2}$ or Fisher's exact test. Factors associated with the use of HCR versus BIMA or SIMA were identified using multivariable logistic regression. Model discrimination was tested by calculation of a c-index corresponding to the area under the receiver operating characteristic curve. This index describes the possibility that for a randomly chosen pair of patients in which one underwent HCR and the other did not, the model correctly found a higher probability in the patient who underwent HCR. Comparisons for in-hospital outcomes and 30-day MACCE were performed using logistic regression analyses, accounting for confounding using STS risk score models (STS-predicted risk of mortality [PROM]). Individual short-term outcomes, Kaplan-Meier survival curves, and Cox proportional hazard regression curves were adjusted for patient factors as noted in the tables and figures. The proportional hazards assumptions were evaluated by visual assessment of log minus log survival plots and were found valid.

In addition to these multivariable adjusted logistic and linear regression analyses, we also performed a propensity score-matched analysis. Propensity scores (or the probability of assignment to HCR or BIMA/ SIMA) were calculated using multivariable logistic regression for each patient, using the variables listed in Table 1. Each patient who underwent HCR was matched to a patient who underwent SIMA as well as separately to a patient who underwent BIMA, using a nearest-neighbor matching algorithm without replacement on the logit of the propensity score. The groups were well balanced after propensity score matching, as assessed by the absolute standardized difference for each covariate (which was $<15 \%$ for all covariables). We also assessed global imbalance, and found it to be not significant (for HCR:BIMA and HCR:SIMA matched pairs, respectively: $P=.69$ and .99 by the Hansen and Bowers test, and 
TABLE 2. Procedure characteristics

\begin{tabular}{|c|c|c|c|c|c|c|c|}
\hline \multirow[b]{2}{*}{ Variable } & \multicolumn{4}{|c|}{ Complete study population } & \multicolumn{3}{|c|}{ Matched study population } \\
\hline & $\begin{array}{c}\text { HCR } \\
(n=306)\end{array}$ & $\begin{array}{c}\text { BIMA } \\
(\mathbf{n}=\mathbf{8 7 3})\end{array}$ & $\begin{array}{c}\text { SIMA } \\
(n=7381)\end{array}$ & $P$ value & $\begin{array}{c}\text { HCR } \\
(n=306)\end{array}$ & $\begin{array}{c}\text { BIMA } \\
(\mathbf{n}=\mathbf{3 0 6})\end{array}$ & $\begin{array}{c}\text { SIMA } \\
(\mathbf{n}=\mathbf{3 0 6})\end{array}$ \\
\hline Elective procedure, $\mathrm{n}(\%)$ & $199(65)$ & $487(55.8)$ & $3906(52.9)$ & $<.001$ & $199(65)$ & $203(66.3)$ & $205(67.0)$ \\
\hline $\mathrm{CPB}, \mathrm{n}(\%)$ & - & $164(18.8)$ & $2487(33.7)$ & $<.001$ & - & $20(6.5)$ & $64(20.9)$ \\
\hline No. of distal anastomoses, mean $\pm \mathrm{SD}$ & $1.1 \pm 0.2$ & $3.7 \pm 1.0$ & $3.3 \pm 0.9$ & $<.001$ & $1.1 \pm 0.2$ & $3.5 \pm 1.0$ & $3.0 \pm 0.9$ \\
\hline No. SVG, mean \pm SD & - & $1.1 \pm 1.0$ & $2.1 \pm 0.9$ & $<.001$ & - & $1.0 \pm 0.9$ & $1.9 \pm 0.9$ \\
\hline DES use, $\mathrm{n}(\%)$ & $256(83.7)$ & - & - & - & $256(83.7)$ & - & - \\
\hline
\end{tabular}

HCR, Hybrid coronary revascularization; BIMA, bilateral internal mammary artery; SIMA, single internal mammary artery; $C P B$, cardiopulmonary bypass; $S D$, standard deviation; $S V G$, saphenous vein graft; $D E S$, drug eluting stent.

$P=1.00$ and 1.00 by the Iacus, King, and Porro test). ${ }^{20,21}$ Probability was significant at a level of $<.05$, and all statistical tests were 2-tailed. Statistical analyses were performed with SPSS version 20.0 (IBM, Armonk, NY).

\section{RESULTS}

After exclusion based on criteria in Figure 1, a total of 8560 patients composed the study population, of whom $306(3.6 \%)$ underwent HCR, $873(10.2 \%)$ underwent CABG with BIMA, and $7381(86.3 \%)$ underwent CABG with SIMA. Preoperative patient characteristics are displayed in Table 1 . The prevalence of morbid obesity was similar in the 3 groups, but was lower in the HCR and BIMA groups, reflective of our selection criteria (BMI >35: HCR, $10.8 \%$ [33 of 306]; SIMA, 15.4\% [1139 of 7375]; BIMA, 12.1\% [106 of 873]). BIMA was generally reserved for younger patients, but at the discretion of the surgeon, some older patients did undergo BIMA grafting (age $\geq 70$ years, $\mathrm{n}=130[14.9 \%$ ]; age $\geq 80$ years, $\mathrm{n}=10$ [1.14\%]). Compared with patients who underwent CABG with BIMA or HCR, those who underwent CABG with SIMA had significantly higher STS PROM (2.1 vs 1.1 and $1.6 ; P<.001)$ and higher rates of diabetes mellitus $(43.8 \%$ vs $27.6 \%$ and $36.9 \% ; P<.001)$, peripheral artery disease $(16.4 \%$ vs $11.1 \%$ and $11.1 \% ; P<.001)$, previous MI $(53.5 \%$ vs $46.4 \%$ and $47.4 \% ; P<.001)$, and heart failure $(24.0 \%$ vs $13.2 \%$ and $12.4 \%$ : $P<.001)$.

Operative details for each group are summarized in Table 2. Cardiopulmonary bypass (CPB) use was lower in the BIMA group compared with the SIMA group $(18.8 \%$ vs $33.7 \% ; P<.001)$, and $\mathrm{CPB}$ was not used in any patients in the HCR group. In the HCR group, the majority of nonLAD lesions were treated with DESs $(n=256 ; 83.7 \%)$. The circumflex or branch vessels were stented in $125 \mathrm{pa}-$ tients $(40.8 \%)$, the right coronary or branch vessels were stented in 142 patients $(46.4 \%)$, the left main coronary was stented in 53 patients $(17.3 \%)$, and the diagonal branch was stented in 34 patients $(11.1 \%)$. More than 1 vessel was stented in 67 patients $(21.9 \%)$. A PCI-first strategy was implemented before minimally invasive LIMA-LAD grafting in 59 of 306 patients (19.3\%) who presented with an acute coronary syndrome in which the culprit lesion was in either the right coronary or circumflex coronary distribution. Seven patients $(2.3 \%)$ underwent conversion to sternotomy for multivessel CABG. Reasons for conversion to sternotomy included LIMA injury during harvest $(\mathrm{n}=2)$, technical difficulties during anastomosis $(\mathrm{n}=3)$, left-sided chest adhesions $(\mathrm{n}=1)$, and inadvertent diagonal grafting $(\mathrm{n}=1)$.

\section{Patient Factors Associated With Use of HCR}

Using all available baseline characteristics, we identified preoperative patient characteristics that were associated

TABLE 3. Preoperative patient factors favoring use of HCR

\begin{tabular}{lrrrr}
\hline \multicolumn{1}{c}{ Variable } & Wald & OR & $\mathbf{9 5} \%$ CI & $\boldsymbol{P}$ value \\
\hline HCR vs BIMA & & & & \\
Three-vessel disease & 61 & 0.24 & $0.17-0.35$ & $<.001$ \\
Previous PCI & 22 & 2.39 & $1.66-3.43$ & $<.001$ \\
Age $>75$ y & 20 & 1.24 & $1.13-1.37$ & $<.001$ \\
Female sex & 14 & 2.07 & $1.41-3.05$ & $<.001$ \\
Hypertension & 9 & 2.42 & $1.38-4.24$ & .002 \\
BMI (per unit) & 8 & 0.96 & $0.92-0.99$ & .006 \\
Dyslipidemia & 7 & 0.44 & $0.24-0.80$ & .007 \\
Diabetes & 7 & 1.57 & $1.12-2.20$ & .010 \\
Left main + other vessel & 6 & 0.52 & $0.30-0.88$ & .014 \\
Elective status & 5 & 1.46 & $1.04-2.04$ & .027 \\
Isolated left main disease & 5 & 0.55 & $0.32-0.95$ & .031 \\
HCR vs SIMA & & & & \\
Three-vessel disease & 81 & 0.28 & $0.21-0.37$ & $<.001$ \\
Previous PCI & 32 & 2.18 & $1.67-2.85$ & $<.001$ \\
Dyslipidemia & 11 & 0.45 & $0.28-0.73$ & .001 \\
Isolated left main disease & 11 & 0.50 & $0.33-0.76$ & .001 \\
Age $>75$ y & 10 & 1.09 & $1.03-1.14$ & .001 \\
Left main + other vessel & 10 & 0.48 & $0.30-0.75$ & .001 \\
Heart failure within previous $14 \mathrm{~d}$ & 8 & 0.56 & $0.38-0.83$ & .004 \\
BMI (per unit) & 8 & 0.97 & $0.95-0.99$ & .005 \\
Hypertension & 5 & 1.72 & $1.07-2.78$ & .026 \\
\hline
\end{tabular}

The following variables were included in these models: age $>75 \mathrm{y}$, female sex, Caucasian race, BMI, current smoker, diabetes, cerebrovascular disease, moderate or severe chronic lung disease, dyslipidemia, hypertension, peripheral artery disease, estimated glomerular filtration rate $<30$, anemia, hematocrit $<0.35$, previous $\mathrm{PCI}$, previous myocardial infarction, heart failure within the previous $14 \mathrm{~d}$, left ventricular ejection fraction $<35 \%, 3$-vessel disease, isolated left main disease, left main disease plus additional coronary artery disease, and elective or urgent status of procedure. $O R$, Odds ratio; $C I$, confidence interval; $H C R$, hybrid coronary revascularization; $B I M A$, bilateral internal mammary artery; $P C I$, percutaneous coronary intervention; $B M I$, body mass index; SIMA, single internal mammary artery. 
TABLE 4. Short-term outcomes and recovery parameters in the total study population $(\mathbf{n}=8560)$

\begin{tabular}{|c|c|c|c|c|c|c|c|}
\hline & \multirow[b]{2}{*}{$\begin{array}{c}\text { HCR }(\mathbf{n}=\mathbf{3 0 6}), \\
\text { n }(\%)\end{array}$} & \multirow[b]{2}{*}{$\begin{array}{c}\text { BIMA }(\mathbf{n}=\mathbf{8 7 3}), \\
\mathbf{n}(\%)\end{array}$} & \multirow[b]{2}{*}{$\begin{array}{c}\text { SIMA }(\mathbf{n}=\mathbf{7 3 8 1}), \\
\mathbf{n}(\%)\end{array}$} & \multicolumn{2}{|c|}{ HCR vs BIMA } & \multicolumn{2}{|c|}{ HCR vs SIMA } \\
\hline & & & & OR $(95 \%$ CI $)$ & $\begin{array}{c}P \\
\text { value }\end{array}$ & OR $(95 \%$ CI $)$ & $\begin{array}{c}P \\
\text { value }\end{array}$ \\
\hline $\operatorname{MACCE}(30 \mathrm{~d})$ & $10(3.3)$ & $19(2.2)$ & $256(3.5)$ & $1.31(0.59-2.90)^{*}$ & .51 & $1.05(0.55-2.00)^{*}$ & .89 \\
\hline All-cause mortality & $5(1.6)$ & $6(0.7)$ & $103(1.4)$ & $2.05(0.55-7.66) \dagger$ & .28 & $1.29(0.52-3.19) \dagger$ & .59 \\
\hline Myocardial infarction & $2(0.7)$ & $8(0.9)$ & $51(0.7)$ & $0.79(0.17-3.75)^{*}$ & .77 & $0.95(0.23-3.91)^{*}$ & .94 \\
\hline Permanent stroke & $3(1.0)$ & $6(0.7)$ & $124(1.7)$ & $1.38(0.34-5.57) \ddagger$ & .65 & $0.59(0.19-1.88) \ddagger$ & .38 \\
\hline In-hospital complications & $26(8.5)$ & $132(15.5)$ & $1233(16.7)$ & $0.43(0.27-0.68)^{*}$ & $<.001$ & $0.53(0.35-0.80)^{*}$ & .003 \\
\hline Renal failure & $5(1.7)$ & $21(2.4)$ & $223(3.0)$ & $0.53(0.18-1.58) \S$ & .26 & $0.54(0.22-1.31) \S$ & .17 \\
\hline Ventilation $>24 \mathrm{~h}$ & $16(5.3)$ & $95(10.9)$ & $943(12.8)$ & $0.33(0.18-0.59) \|$ & $<.001$ & $0.41(0.24-0.69) \|$ & .001 \\
\hline Deep sternal infection & $0.0(0)$ & $24(2.7)$ & $137(1.9)$ & - & - & - & - \\
\hline Reoperation & $13(4.2)$ & $24(2.7)$ & $354(4.8)$ & $1.43(0.71-2.88) \rrbracket$ & .31 & $0.99(0.56-1.75) \Phi$ & .97 \\
\hline \multicolumn{8}{|l|}{ Bleeding events } \\
\hline CABG-related bleeding & $22(7.2)$ & $47(5.4)$ & $752(10.2)$ & $1.16(0.65-2.04) \#$ & .62 & $0.75(0.48-1.17) \#$ & .20 \\
\hline Any blood transfusion & $75(24.5)$ & $344(39.4)$ & $3992(54.1)$ & 0.25 (0.17-0.36)\# & $<.001$ & $0.23(0.18-0.31) \#$ & $<.001$ \\
\hline \multicolumn{8}{|l|}{ Recovery parameters } \\
\hline PLOS $<5 d$ & $161(52.6)$ & $374(42.8)$ & $2556(34.6)$ & $1.93(1.46-2.56)^{* *}$ & $<.001$ & $1.92(1.50-2.47)^{* * *}$ & $<.001$ \\
\hline PLOS $>14 d$ & $7(2.3)$ & $33(3.8)$ & $391(5.3)$ & $0.50(0.21-1.17) \dagger \dagger$ & .11 & $0.46(0.22-1.00) \dagger \dagger$ & .04 \\
\hline
\end{tabular}

HCR, Hybrid coronary revascularization; BIMA, bilateral internal mammary artery; SIMA, single internal mammary artery; $O R$, odds ratio; $C I$, confidence interval; $M A C C E$, major cerebrovascular and cardiac event; $C A B G$, coronary artery bypass grafting; $P L O S$, postoperative length of stay. *Adjusted for STS-predicted morbidity or mortality score. $\dagger$ Adjusted for STS-predicted mortality. $\ddagger$ Adjusted for STS-predicted stroke score. §Adjusted for STS-predicted renal failure score. $\|$ Adjusted for STS-predicted prolonged ventilation score. ISTS reoperation score. \#STS-predicted morbidity or mortality, patient age, sex, anemia, hematocrit $<35 \%$, estimated glomerular filtration rate $<60$, and diabetic status. **STS short PLOS score. ††STS long PLOS score.

with the use of HCR versus CABG with BIMA or SIMA. The c-statistic for these models was 0.80 and 0.76 , respectively, indicating that the variables used explained most of the variability in the selection of revascularization procedure. The predictors are shown in Table 3. Overall, the models suggest that HCR is preferred in older patients with lower BMI, a history of previous PCI, hypertension, and stable 2-vessel disease. Compared with BIMA, HCR was also more frequently preferred in patients with diabetes.

\section{Short-Term Outcomes and Recovery Parameters}

The unadjusted rates for the composite endpoint 30-day MACCE were $3.3 \%(n=10)$ for HCR, $2.2 \%(n=19)$ for BIMA, and 3.5\% $(\mathrm{n}=256)$ for SIMA (Tables 4 and 5$)$. Multivariate analysis controlling for STS PROM and STS-predicted risk of morbidity/mortality demonstrated no differences between HCR and BIMA (odds ratio [OR], $1.31 ; P=.51)$ or between HCR and SIMA (OR, 1.05; $P=.89$ ). There were fewer perioperative in-hospital complications in the HCR group compared with the other 2 groups after adjustment (HCR vs BIMA: OR, 0.43; $P<.001$; HCR vs SIMA: OR, $0.53 ; P=.003)$. HCR was associated with a shorter PLOS ( $<5$ days) compared with BIMA (OR, 1.93; $P<.001)$ and SIMA (OR, 1.92; $P<.001)$, and with fewer blood transfusions compared with BIMA (OR, 0.25; $P<.001$ ) and SIMA (OR, 0.23; $P<.001)$. Two patients in the HCR group experienced stent thrombosis, which resulted in nonfatal MI. Of the 3 postoperative strokes in the HCR group, 2 occurred in the postoperative period, 1 of which was an exacerbation in a patient who experienced preoperative stroke. In 1 patient, the etiology was emboli associated with percutaneous carotid stenting, which occurred during a combined hybrid coronary/carotid procedure. All of these patients had only mild deficits that resolved by the time of discharge.

After adjusting for all available confounding variables, the short-term outcomes and recovery parameters differed between the HCR and BIMA/SIMA groups in a similar fashion as for propensity score-matched groups. The composite endpoint of 30-day MACCE was similar in the matched populations (HCR vs BIMA: OR, $2.50 ; P=.12$; HCR vs SIMA: OR, $1.00 ; P=1.00$ ). Similar to adjusted outcomes in the unmatched cohorts, the HCR propensity score-matched population had lower in-hospital complication rates (HCR vs BIMA: OR, $0.55 ; P=.015$; HCR vs SIMA: OR, 0.59; $P=.033$ ), less need for blood transfusion (HCR vs BIMA: OR, 0.57; $P<.001 ; \mathrm{HCR}$ vs SIMA: OR, $0.44 ; P<.001)$, and was more frequently associated with PLOS $<5$ days (HCR vs BIMA: OR, $1.40 ; P=.006 ;$ HCR vs SIMA: OR, $1.28 ; P=.038$ ).

\section{Longitudinal Clinical Outcomes}

In the propensity score matched-cohort, all-cause mortality at maximum follow-up of 5 years was similar in the 3 groups as estimated by Kaplan-Meier curves (HCR, $11.5 \%$; BIMA, $10.1 \%$; SIMA, $13.6 \%$ ) (Figure 2). Because our data acquisition took place on January 1, 2011, before the Social Security Death Index dataset expungement in November 2011, we limited our analysis to this time period 
TABLE 5. Short-term outcomes and recovery parameters in the propensity score-matched population $(\mathrm{n}=918)$

\begin{tabular}{|c|c|c|c|c|c|c|c|}
\hline \multirow[b]{2}{*}{ Outcome } & \multirow[b]{2}{*}{$\begin{array}{c}\text { HCR }(\mathbf{n}=\mathbf{3 0 6}), \\
\mathbf{n}(\%)\end{array}$} & \multirow[b]{2}{*}{$\begin{array}{c}\text { BIMA }(\mathbf{n}=306), \\
\text { n }(\%)\end{array}$} & \multirow[b]{2}{*}{$\begin{array}{c}\text { SIMA }(\mathbf{n}=\mathbf{3 0 6}), \\
\mathbf{n}(\%)\end{array}$} & \multicolumn{2}{|c|}{ HCR vs BIMA } & \multicolumn{2}{|c|}{ HCR vs SIMA } \\
\hline & & & & OR $(95 \%$ CI $)$ & $\begin{array}{c}P \\
\text { value }\end{array}$ & OR $(95 \%$ CI $)$ & $\begin{array}{c}P \\
\text { value }\end{array}$ \\
\hline MACCE (30 d) & $10(3.3)$ & $4(1.3)$ & $11(3.6)$ & $2.50(0.78-7.91)$ & .12 & $1.00(0.42-2.40)$ & 1.00 \\
\hline All-cause mortality & $5(1.6)$ & $2(0.7)$ & $6(2.0)$ & $2.50(0.49-12.89)$ & .27 & $1.00(0.29-3.45)$ & 1.00 \\
\hline Myocardial infarction & $2(0.7)$ & $1(0.3)$ & $1(0.3)$ & $2.00(0.18-22.06)$ & .57 & $2.00(0.18-22.06)$ & .57 \\
\hline Permanent stroke & $3(1.0)$ & $1(0.3)$ & $4(1.3)$ & $3.00(0.31-28.8)$ & .34 & $0.75(0.17-3.35)$ & .71 \\
\hline In-hospital complications & $26(8.5)$ & $47(15.4)$ & $46(15.0)$ & $0.55(0.34-0.89)$ & .015 & $0.59(0.36-0.96)$ & .033 \\
\hline Renal failure & $5(1.7)$ & $9(2.9)$ & $9(2.9)$ & $0.63(0.20-1.91)$ & .41 & $0.56(0.19-1.66)$ & .29 \\
\hline Ventilation $>24 \mathrm{~h}$ & $16(5.3)$ & $37(12.1)$ & $38(12.4)$ & $0.44(0.25-0.80)$ & .007 & $0.44(0.25-0.80)$ & .007 \\
\hline Deep sternal infection & $0(0.0)$ & $8(2.6)$ & $3(1.0)$ & - & - & - & - \\
\hline Reoperation & $13(4.2)$ & $7(2.3)$ & $11(3.6)$ & $1.86(0.74-4.66)$ & .19 & $1.18(0.53-2.64)$ & .68 \\
\hline \multicolumn{8}{|l|}{ Bleeding events } \\
\hline CABG-related bleeding & $22(7.2)$ & $23(7.5)$ & $23(7.5)$ & $0.96(0.53-1.72)$ & .88 & $0.96(0.53-1.72)$ & .88 \\
\hline Any blood transfusion & $75(24.5)$ & $131(42.8)$ & $168(54.9)$ & $0.57(0.43-0.76)$ & $<.001$ & $0.44(0.34-0.59)$ & $<.001$ \\
\hline \multicolumn{8}{|l|}{ Recovery parameters } \\
\hline PLOS $<5 d$ & $161(52.6)$ & $115(37.6)$ & $125(40.8)$ & $1.40(1.10-1.78)$ & .006 & $1.28(1.01-1.62)$ & .038 \\
\hline PLOS $>14 \mathrm{~d}$ & $7(2.3)$ & $11(3.6)$ & $11(3.6)$ & $0.64(0.25-1.64)$ & .35 & $0.64(0.25-1.64)$ & .35 \\
\hline
\end{tabular}

$\overline{H C R}$, Hybrid coronary revascularization; BIMA, bilateral internal mammary artery; SIMA, single internal mammary artery; OR, odds ratio; $C I$, confidence interval; $M A C C E$, major cerebrovascular and cardiac event; $C A B G$, coronary artery bypass graft; PLOS, postoperative length of stay.

for all groups. Median follow-up was 2.83 years (interquartile range, 1.18-4.91 years). After adjustment for all potential confounding variables available, there was no significant difference among the groups in the hazard ratio (HR) for all-cause mortality at 5 years (HCR vs BIMA: HR, 1.05; 95\% confidence interval $[\mathrm{CI}], 0.48-2.29, P=.91$; HCR vs SIMA: HR, 0.66; 95\% CI, 0.32-1.38; $P=.66)$.

\section{DISCUSSION}

The findings of this single-center retrospective cohort study of more than 8500 patients undergoing surgical coronary revascularization can be summarized as follows: (1) factors favoring the decision to use HCR were older age, lower BMI, a history of previous PCI, and less extensive CAD; (2) compared with CABG using either BIMA or SIMA grafts, HCR was associated with comparable outcomes for the composite endpoint of MACCE, as well as all-cause mortality at 30 days; (3) HCR was associated with fewer in-hospital complications and shorter PLOS compared with traditional CABG; and (4) HCR had comparable midterm survival to BIMA and SIMA in the propensity score-matched comparison. Although these results are encouraging for $\mathrm{HCR}$ as an alternative revascularization strategy, longer-term follow-up data and more direct comparisons for specific patient subgroups defined by coronary anatomy and patient comorbidities are needed before definitive conclusions can be drawn.

We reported our HCR patient selection criteria previously, and recent reviews provide guidelines. ${ }^{16,17,22}$ Our use of statistical modeling in the present study confirms those preoperative patient factors that make it more likely for the heart team at our institution to select
HCR versus traditional CABG with SIMA or BIMA. In our analysis, older patients, those with lower BMI or previous PCI, and those with stable 2-vessel disease were more likely to undergo HCR. Other studies have reported better quality of life scores and functional recovery in patients undergoing minimally invasive HCR compared with those undergoing traditional $\mathrm{CABG} .{ }^{23-25} \mathrm{HCR}$ is safe even in selected high-risk patients. In a cohort of 50 patients undergoing HCR with a mean STS PROM risk of $4.3 \%$, the 30 -day mortality was $2 \%$, only $40 \%$ of patients required blood product transfusion, and there were no superficial or deep sternal wound infections. ${ }^{26}$

Previous studies on outcomes in HCR versus traditional $\mathrm{CABG}$ predominantly compared patients in whom CABG was performed using LIMA plus SVG. A recent meta-analysis of more than 1100 patients from 6 observational cohort studies found similar outcomes in patients undergoing HCR and those undergoing CABG, as measured by a composite of death, MI, stroke, and repeat revascularization during hospitalization (OR, 0.63; 95\% CI, $0.25-0.158, P=.33$ ), as well as at 1 -year follow-up (OR, 0.49; 95\% CI, 0.20-1.24; $P=.13$ ). ${ }^{8}$ HCR was associated with less in-hospital need for blood transfusions, shorter PLOS, and faster return to work. Our study demonstrates similar outcomes (both short-term and midterm) in HCR versus CABG with SIMA or BIMA conduits, confirming that this is a safe approach for appropriately selected patients. Here the main short-term advantage of HCR was a lower incidence of perioperative complications, including fewer blood transfusions, no deep sternal wound infections, shorter ventilation time, and shorter PLOS. 


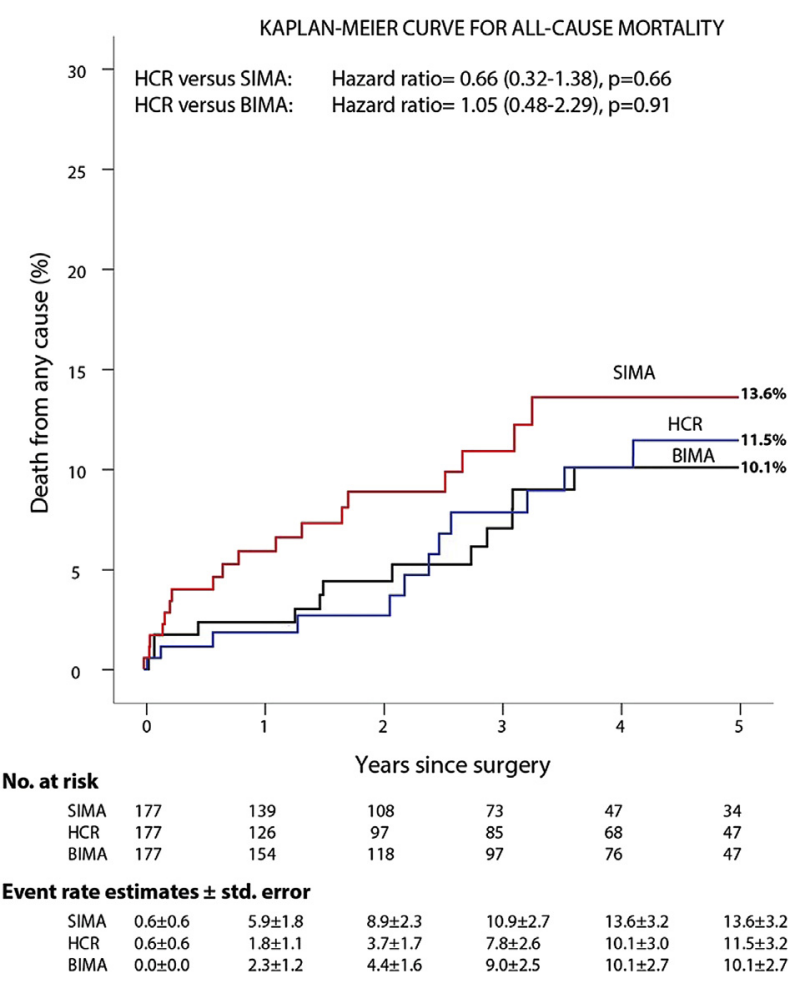

FIGURE 2. Kaplan-Meier estimates for longitudinal outcomes after HCR, SIMA- CABG, and BIMA-CABG. The hazard ratios were adjusted for age, sex, year of procedure, BMI $>30$, diabetes, cerebrovascular disease, peripheral artery disease, chronic lung disease, renal failure, previous MI, heart failure within 14 days, hematocrit $<35 \%$, anemia, left ventricular ejection fraction $<35 \%$, left main disease, 3 -vessel disease, elective or urgent procedure, and STS-predicted risk of mortality; with a median follow-up of 2.83 years (IQR, 1.18-4.91 years). HCR, Hybrid coronary revascularization; SIMA, single internal mammary artery; $B I M A$, bilateral internal mammary artery.

Results from a recent meta-analysis of 70,897 patients show that use of BIMA conduits may reduce long-term mortality by $20 \%$ compared with SIMA. ${ }^{27}$ Despite a perceived increase in technical difficulty and a higher risk of postoperative wound infection with the use of BIMA in patients with poorly controlled diabetes, convincing evidence has mounted showing long-term benefits for surgical coronary revascularization with multiple arterial conduits when possible compared with a combination of SIMA and multiple venous grafts. ${ }^{28-30}$ The potential benefits of a multiarterial grafting strategy are becoming more apparent, and more definitive data will be obtained when 10-year survival results from the Arterial Revascularization Trial (ART) are presented in 2018. ${ }^{13,14}$ In our cohort, the all-cause mortality rate was lower in the BIMA group compared with the HCR and SIMA groups, but these patients were younger, and when controlling for preoperative comorbidities, there was no significant difference in survival among the groups (Figure 2). A study from Benedetto and colleagues ${ }^{31}$ has corroborated our findings, demonstrating similar operative morbidity and mortality between SIMA and BIMA with improved midterm survival (mean follow-up, $4.8 \pm 3.2$ years) in a propensity score-matched BIMA cohort. Longer-term follow-up and randomized trial data are needed to adjudicate these preliminary findings.

We propose that for appropriately selected patients based on coronary anatomy, lesion complexity, and patient-related variables, the HCR approach may provide similar short-term and midterm results as CABG with SIMA or BIMA, with fewer perioperative complications and improved short-term outcomes. These patients include those who may be at greater risk for postoperative complications with sternotomy $\mathrm{CABG}$, as well as those with non-LAD lesions that may be well suited for PCI. Furthermore, patients with 2-vessel disease involving the proximal LAD may be ideal candidates for HCR, especially when the non-LAD lesion is a focal right coronary lesion that otherwise would be treated with PCI. One caveat of HCR involves gaining expertise in minimally invasive CABG procedures for LIMA-LAD grafting, which may limit the adoption of this revascularization strategy.

These data have important prognostic implications and need to be considered by surgeons who perform minimally invasive CABG as part of HCR. For example, patients with severe disease and an amenable second left-sided target lesion may be best treated with traditional CABG with multiple arterial conduits, whereas a patient with a focal right coronary artery lesion and proximal LAD disease may be treated by HCR. Our present results cannot confirm these hypotheses; nevertheless, we contend that HCR offers surgeons an additional safe and durable option for patients with multivessel CAD referred for surgical intervention, especially those for being considered for multivessel PCI with proximal LAD disease. Despite the evidence supporting surgical revascularization for patients with multivessel disease, multivessel PCI is still routinely performed. For patients that are not candidates for a multiarterial grafting strategy or for those insistent on a minimally invasive option, surgeons can still provide the major survival benefit of CABG with minimally invasive LIMA-LAD grafting as part of an HCR approach in patients with non-LAD anatomy amenable to PCI.

This study has several limitations. Because it is a retrospective study, treatment allocation was not randomized, but rather was based on clinical judgment by individual surgeons and cardiologists. To account for confounding, outcomes were adjusted for a number of preoperative baseline characteristics, but residual or unmeasured confounding may be present. Because the data for this study were derived from the STS database, elaborate details of individual patient coronary anatomy and details of PCI decision making are unavailable. The STS dataset used for this study did not contain the SYNTAX 
score, fractional flow reserve measures, or individual lesion complexity for all patients; however, we have included angiographic data that would present relevant confounders, namely isolated left main disease, left main plus another vessel, and 3-vessel disease. Although direct comparisons to therapeutic decision making are difficult in large-scale, retrospective dataset analyses, we have included propensity score matching to strengthen our evaluation of the safety of HCR compared with SIMA or BIMA. Although we previously published our initial case series of $\mathrm{HCR},{ }^{17}$ which included repeat revascularization events, this was not included in the present study because of potential bias in these comparisons. HCR patients routinely undergo LIMA-LAD angiography, with reintervention that is not necessarily driven by clinically ischemic events. Furthermore, compared with patients undergoing sternotomy CABG, HCR patients underwent more rigorous follow-up, with all contacted by telephone call. The patients in the SIMA and BIMA groups underwent angiography only for clinically ischemic events. Furthermore, these patients would have had reintervention captured in the STS database only if reintervention had been performed during the index hospitalization or within our healthcare system. Because this analysis was performed with data collected at a large academic medical center with highly experienced operators, generalization of our findings to smaller practices with less volume or expertise with minimally invasive techniques must be done with caution.

For patients with multivessel CAD, HCR may offer a safe and effective alternative revascularization strategy compared with traditional CABG with SIMA or BIMA. HCR is associated with similar midterm outcomes but with shorter hospital PLOS and fewer short-term complications. However, as shown in other published studies, BIMA grafting may provide the most durable long-term results compared with either HCR or SIMA in appropriately selected patients. HCR represents an additional revascularization strategy that may be considered based on the extent of coronary disease, lesion complexity, and patient comorbidities. Further investigation into which patient subgroups may benefit from a now broader range of revascularization options is warranted.

\section{Conflict of Interest Statement}

M.H. has served as a consultant for Intuitive Surgical, Medtronic, and Maquet Cardiovascular. All other authors have nothing to disclose with regard to commercial support.

\section{References}

1. Fihn SD, Gardin JM, Abrams J, Berra K, Blankenship JC, Dallas AP, et al. 2012 ACCF/AHA/ACP/AATS/PCNA/SCAI/STS guideline for the diagnosis and management of patients with stable ischemic heart disease: a report of the American College of Cardiology Foundation/American Heart Association task force on practice guidelines, and the American College of Physicians, American Association for Thoracic Surgery, Preventive Cardiovascular Nurses
Association, Society for Cardiovascular Angiography and Interventions, and Society of Thoracic Surgeons. J Am Coll Cardiol. 2012;60:2564-603.

2. Task Force on Myocardial Revascularization of the European Society of Cardiology (ESC) and the European Association for Cardio-Thoracic Surgery (EACTS); European Association for Percutaneous Cardiovascular Interventions (EAPCI). Guidelines on myocardial revascularization. Eur Heart J. 2010;31: 2501-55.

3. Leacche M, Zhao DX, Umakanthan R, Byrne JG. Do hybrid procedures have proven clinical utility and are they the wave of the future? Hybrid procedures have no proven clinical utility and are not the wave of the future. Circulation. 2012;125:2504-10.

4. Shannon J, Colombo A, Alfieri O. Do hybrid procedures have proven clinical utility and are they the wave of the future? Hybrid procedures have proven clinical utility and are the wave of the future. Circulation. 2012;125: 2492-503.

5. Harskamp RE, Zheng Z, Alexander JH, Williams JB, Xian Y, Halkos ME, et al. Status quo of hybrid coronary revascularization for multi-vessel coronary artery disease. Ann Thorac Surg. 2013;96:2268-77.

6. Farooq V, Serruys PW, Zhang Y, Mack M, Ståhle E, Holmes DR, et al. Short-term and long-term clinical impact of stent thrombosis and graft occlusion in the SYNTAX trial at 5 years: Synergy Between Percutaneous Coronary Intervention with Taxus and Cardiac Surgery trial. J Am Coll Cardiol. 2013;62:2360-9.

7. Halkos ME, Vassiliades TA, Douglas JS, Morris DC, Rab ST, Liberman HA, et al. Hybrid coronary revascularization versus off-pump coronary artery bypass grafting for the treatment of multivessel coronary artery disease. Ann Thorac Surg. 2011;92:1695-701.

8. Harskamp RE, Bagai A, Halkos ME, Rao SV, Bachinsky WB, Patel MR, et al. Clinical outcomes after hybrid coronary revascularization versus coronary artery bypass surgery: a meta-analysis of 1,190 patients. Am Heart J. 2014; 167:585-92.

9. Harskamp RE, Puskas JD, Tijssen JG, Walker PF, Liberman HA, Lopes RD, et al. Comparison of hybrid coronary revascularization versus coronary artery bypass grafting in patients $>65$ years with multivessel coronary artery disease. Am J Cardiol. 2014;114:224-9.

10. Tatoulis J, Buxton BF, Fuller JA. The right internal thoracic artery: the forgotten conduit—5,766 patients and 991 angiograms. Ann Thorac Surg. 2011;92:9-15.

11. Weiss AJ, Zhao S, Tian DH, Taggart DP, Yan TD. A meta-analysis comparing bilateral internal mammary artery with left internal mammary artery for coronary artery bypass grafting. Ann Cardiothorac Surg. 2013;2:390-400.

12. Raza S, Sabik JF III, Masabni K, Ainkaran P, Lytle BW, Blackstone EH. Surgical revascularization techniques that minimize surgical risk and maximize late survival after coronary artery bypass grafting in patients with diabetes mellitus. J Thorac Cardiovasc Surg. 2014;148:1257-64.

13. Halkos ME, Guyton RA. Coronary bypass: is it time to take the next step-the routine use of the second arterial graft? J Thorac Cardiovasc Surg. 2014;148: $1149-51$.

14. Taggart DP, Altman DG, Gray AM, Lees B, Nugara F, Yu LM, et al. Randomized trial to compare bilateral vs. single internal mammary coronary artery bypass grafting: 1-year results of the Arterial Revascularisation Trial (ART). Eur Heart J. 2010;31:2470-81.

15. Harskamp RE, Vassiliades TA, Mehta RH, de Winter RJ, Lopes RD, Xian Y, et al. Comparative effectiveness of hybrid coronary revascularization vs coronary artery bypass grafting. J Am Coll Surg. 2015;221:326-34.e1.

16. Vassiliades TA Jr, Douglas JS, Morris DC, Block PC, Ghazzal Z, Rab ST, et al. Integrated coronary revascularization with drug-eluting stents: immediate and seven-month outcome. J Thorac Cardiovasc Surg. 2006;131:956-62.

17. Halkos ME, Walker PF, Vassiliades TA, Douglas JS, Devireddy C, Guyton RA, et al. Clinical and angiographic results after hybrid coronary revascularization. Ann Thorac Surg. 2014;97:484-90.

18. Halkos ME, Thourani VH, Lattouf OM, Kilgo P, Guyton RA, Puskas JD. Preoperative hemoglobin Alc predicts sternal wound infection after coronary artery bypass surgery with bilateral versus single internal thoracic artery grafts. Innovations (Phila). 2008;3:131-8.

19. Mehran R, Rao SV, Bhatt DL, Gibson CM, Caixeta A, Eikelboom J, et al. Standardized bleeding definitions for cardiovascular clinical trials: a consensus report from the Bleeding Academic Research Consortium. Circulation. 2011; $123: 2736-47$.

20. Blackstone EH. Comparing apples and oranges. J Thorac Cardiovasc Surg. 2002; 123:8-15.

21. Rubin DB. Estimating causal effects from large data sets using propensity scores. Ann Intern Med. 1997;127:757-63. 
22. Panoulas VF, Colombo A, Margonato A, Maisano F. Hybrid coronary revascularization: promising, but yet to take off. J Am Coll Cardiol. 2015;65: $85-97$.

23. Bachinsky WB, Abdelsalam M, Boga G, Kiljanek L, Mumtaz M, McCarty C. Comparative study of same sitting hybrid coronary artery revascularization versus off-pump coronary artery bypass in multivessel coronary artery disease. J Interv Cardiol. 2012;25:460-8.

24. Kon ZN, Brown EN, Tran R, Joshi A, Reicher B, Grant MC, et al. Simultaneous hybrid coronary revascularization reduces postoperative morbidity compared with results from conventional off-pump coronary artery bypass. J Thorac Cardiovasc Surg. 2008;135:367-75.

25. de Cannière D, Jansens JL, Goldschmidt-Clermont P, Barvais L, Decroly P, Stoupel E. Combination of minimally invasive coronary bypass and percutaneous transluminal coronary angioplasty in the treatment of double-vessel coronary disease: two-year follow-up of a new hybrid procedure compared with "on-pump" double-bypass grafting. Am Heart J. 2001;142:563-70.

26. Halkos ME, Liberman HA, Devireddy C, Walker P, Finn AV, Jaber W, et al. Early clinical and angiographic outcomes after robotic-assisted coronary artery bypass surgery. J Thorac Cardiovasc Surg. 2014;147:179-85.
27. Takagi H, Goto SN, Watanabe T, Mizuno Y, Kawai N, Umemoto $T$ A meta-analysis of adjusted hazard ratios from 20 observational studies of bilateral versus single internal thoracic artery coronary artery bypass grafting. J Thorac Cardiovasc Surg. 2014;148:1282-90.

28. Buxton BF, Shi WY, Tatoulis J, Fuller JA, Rosalion A, Hayward PA. Total arterial revascularization with internal thoracic and radial artery grafts in triple-vessel coronary artery disease is associated with improved survival. J Thorac Cardiovasc Surg. 2014;148:1238-43.

29. Johnston DR. Long-term results of multiple arterial bypass conduits. Curr Opin Cardiol. 2014:29:542-6.

30. Hirose H, Amano A, Takanashi S, Takahashi A. Skeletonized bilateral internal mammary artery grafting for patients with diabetes. Interact Cardiovasc Thorac Surg. 2003;2:287-92.

31. Benedetto U, Amrani M, Gaer J, Bahrami T, de Robertis F, Simon AR, et al. The influence of bilateral internal mammary arteries on short- and long-term outcomes: a propensity score matching in accordance with current recommendations. J Thorac Cardiovasc Surg. 2014;148:2699-705.

Key Words: CAB, hybrid coronary revascularization, bilateral internal thoracic arteries, PCI

Readers who found these articles interesting may also like to read the following papers found in recent and future issues of our sister publications, Seminars in Thoracic and Cardiovascular Surgery and Operative Techniques in Thoracic and Cardiovascular Surgery!

\section{Acquired: Coronary Artery Disease}

Original Submissions: Micromorphology of Skeletonized and Pedicled Internal Thoracic and Radial Arteries. Sergey Mamchur. Semin Thorac Cardiovasc Surg 2015; Summer; 27(2):115-120.

Editorial Commentary: Harvesting Arterial Grafts: Barebones or More. Faisal G. Bakaeen. Semin Thorac Cardiovasc Surg 2015; 27(2):121-122. 